\title{
ANÍSIO TEIXEIRA E OS DESAFIOS DA PRIMEIRA GESTÃo NA INSPETORIA DE ENSINO DA BAHIA (1924-1929)
}

\author{
Sandra Regina Cassol CARBELLO ${ }^{1}$ \\ Ricardo RIBEIRO ${ }^{2}$
}

RESUMO: O presente trabalho integra projeto de pesquisa, ainda em desenvolvimento no curso de doutorado em educação, que resgata as contribuições de Anísio Teixeira para a organização da escola pública brasileira. Para este texto, selecionamos as ações realizadas durante sua primeira experiência na área educacional, quando assumiu a Inspetoria de Ensino da Bahia em 1924. Trata-se de um estudo bibliográfico ancorado nos registros do próprio autor e de demais intelectuais que se dedicaram ao seu legado. Os resultados apontam para as ações de reorganização da escola primária com a elaboração de um programa de ensino e redefinição de seus objetivos e métodos, concomitantemente, ressalta a necessidade de profissionalização e capacitação docente para efetivar a reforma empreendida.

PALAVRAS-CHAVE: Ensino primário. Escola pública. Formação docente.

\section{INTRODUÇÃO}

O presente trabalho integra o projeto de pesquisa desenvolvido no doutoramento em educação que investiga a organização escolar na perspectiva de Anísio Teixeira. O objetivo da investigação é conhecer as contribuições do autor para a organização da escola pública brasileira, especialmente os desafios enfrentados no campo da administração da educação.

Anísio Teixeira esteve no comando da educação baiana em dois momentos distintos: de 1924 a 1929, logo no início de sua carreira na educação, e de 1947 a 1951, quando retornou à vida pública em seu Estado após perseguições políticas. Para este texto optamos em nos atentar aos dados da primeira gestão na Inspetoria de Ensino da Bahia. Estruturamos a narrativa a partir das seguintes questões que conduziram nosso olhar na pesquisa: qual a situação encontrada na primeira gestão da Inspetoria Geral de Ensino? Quais foram as ações para enfrentamento dos problemas encontrados? A partir

\footnotetext{
${ }^{1}$ Professora do Departamento de Fundamentos da Educação. UEM - Universidade Estadual de Maringá. Doutoranda em Educação no Programa de Pós-Graduação em Educação Escolar. UNESP - Universidade Estadual Paulista Júlio de Mesquita Filho, Campus Araraquara. Araraquara - SP - Brasil. 14800-901 sandra.cassol@gmail.com

${ }^{2}$ Professor Orientador do Programa de Pós-Graduação em Educação Escolar. UNESP - Universidade Estadual Paulista. Júlio de Mesquita Filho, Campus Araraquara. Araraquara - SP - Brasil. 14800-901 despertarosol@gmail.com
} 
os registros estudados procuramos sinalizar o trabalho desenvolvido assim como as conquistas e os entraves enfrentados. Nesse caminho, ressaltamos a importância de conhecer o trabalho educacional realizado pelos grandes intelectuais que fazem parte da trajetória da educação brasileira, pois conhecer nossa história nos instrumentaliza para fortalecer o trabalho pela melhoria da educação pública ofertada no país.

\section{A primeira gestão na Inspetoria Geral de Ensino da Bahia}

A primeira gestão de Anísio Teixeira na Inspetoria Geral de Ensino da Bahia iniciou em 19 de abril de 1924, com o convite inesperado de Góes Calmon, recém-eleito governador, para assumir o cargo de Inspetor Geral do Ensino, e se estendeu a novembro de 1929. No auge de sua juventude, com apenas 23 anos, bacharel em Direito, Anísio Teixeira assumiu um dos cargos que por tradição daquele Estado era indicado a profissionais mais velhos e experientes. Ao assumir o cargo:

O jovem titular da Inspetoria do Ensino encontrara uma organização pedagógica rotineira e pobre, 600 escolas elementares isoladas e apenas 1 grupo escolar custeados pelo Estado e cerca de 500 escolas municipais, com a matrícula de 23.428 alunos nas classes estaduais. (LIMA, 1978, p.44).

Anísio Teixeira relatou a situação precária que encontrou e queria reverter no documento intitulado "Sugestões para a reorganização progressiva do sistema educacional baiano": “[...] em mil crianças em idade escolar, apenas duzentas frequentam alguma escola; apenas trinta concluem o curso primário elementar; apenas sete obtêm alguma educação secundária e apenas duas têm os benefícios da educação superior.” (ABREU, 1960, p.32). A situação era caótica, a grande maioria da população em idade escolar estava à margem dela. Sobre o acesso à escola e à informação Lima (1978, p.56) recupera os registros de Anísio e descreve o árido cenário:

[...] excluídos pontos em que despontava certo desenvolvimento agrícola, "a população, escrevia Anísio, vive em completo estado de isolamento e primitivismo. Nem livros, nem jornais, nem estradas lhes levam seja uma ideia nova seja um homem novo para agitar o seu marasmo proverbial. Das instituições tradicionais de civilização nem a Igreja, nem a escola existem. Quando existem, não prestam os serviços esperados, devido já às condições ambientes, já à ineficiência pessoal do encarregado das mesmas". 
Esse quadro configurava-se nas primeiras décadas do século $\mathrm{XX}$ “[...] apesar de a primeira Constituição Estadual Baiana, datada de 2/7/1891, estabelecer no artigo 148, do capítulo I, no título X, a gratuidade e a universalidade do ensino primário." (NUNES, 2010, p.17). Segundo dados apresentados por Teixeira (1928) no Relatório do Serviço de Instrução Pública do Estado da Bahia referente ao quadriênio (1924-1928), a gratuidade e a universalidade contrastavam com os privilégios dos filhos de famílias aristocráticas que tradicionalmente investiam na boa educação dos filhos para legar-lhes prestígio e poder:

Emquanto, nos referimos a esses numeros entristecedores do ensino primario, devemos registrar que a Bahia, que não possuia em 1923 uma escola primaria publica organizada e em condições de efficiencia, nem siquer em sua Capital, contava com um Gymnasio official montado com luxuosa liberalidade se o comparassemos com as classes elementares, varios collegios secundarios particulares, uma Faculdade de Direito, uma Escola Polytechnica e uma Faculdade de Medicina, considerada como uma das mais notaveis do paiz. (TEIXEIRA, 1928).

Esse contraste entre o ensino público desorganizado e insuficiente e o ensino privado organizado e seletivo também é denunciado por Lima (1978, p.45):

Do ensino secundário ocupavam-se sobretudo os colégios particulares, que acolhiam os jovens cujas famílias, colocadas em situação financeira propícia, podiam pagar-lhes os estudos visando os cursos superiores, praticamente reservados às categorias abastadas da sociedade.

No entender de Nunes (2010, p.17): “[...] uma das maiores dificuldades do Inspetor Geral de Ensino, assim, seria romper com a tradição de valorização do ensino particular pelos deputados e senadores estaduais baianos como resposta às deficiências do ensino primário público".

A situação desordenada no quadro educacional do Estado agravava-se com a descrição das poucas escolas que funcionavam. Segundo Nunes (2010) estas escolas estavam concentradas em Salvador, localizadas em antigas residências, muitas em ruínas, pois não havia preocupação com a manutenção. O pagamento dos professores e dos alugueis eram um transtorno, como registram os autores: “[...] era generalizado o costume de o professor custear, com seus próprios recursos, o aluguel da sala ou do prédio em que instalava as 'cadeiras'.” (NUNES, 2010, p.17). “Tão irregular e atrasado 
era o pagamento de professores e alugueis, que o mesmo passou a ser feito pelo Tesouro do Estado". (LIMA, 1978, p.52).

Para além dos problemas com o pagamento dos docentes, com os alugueis dos imóveis que abrigavam as precárias instalações escolares e sua manutenção, havia outros problemas seríssimos para o funcionamento das escolas: os professores e alunos conviviam com a falta de material didático que subsidiasse o trabalho pedagógico, especialmente os livros. “[...] Anísio chegou a presenciar que era comum os estudantes escreverem no chão, estirados de bruços sobre papéis de jornal ou, então, fazerem seus exercícios de joelhos, ao redor de bancos ou à volta das cadeiras". (NUNES, 2010, p.17).

A comunidade escolar se acostumou com as ausências e negligências dos mantenedores: “[...] o governo não oferecia mobiliário escolar, nem o professor a adquiria. Cabia ao aluno fornecer cadeiras e mesas improvisadas com barricas, caixotes, pequenos bancos de tábua, tripeças estreitas e mal equilibradas, cadeiras encouradas ou tecidas a junco.” (NUNES, 2010, p.17). Nestas condições paupérrimas os poucos professores tentavam conduzir o trabalho escolar para os alunos que podiam usufruir dele. Estes podiam ser considerados privilegiados, pois a maioria absoluta estava distante de tudo, até mesmo destes improvisados bancos escolares.

Em relação ao ensino os problemas não eram poucos. Não só na Bahia, como em todo o país, o ensino: “[...] cristalizara-se nas linhas tradicionais de uma instrução primária ministrada em escolas mais de ler e contar que de educar, [...] insuficientes até para alfabetizar a população.” (LIMA, 1978, p.45). Com as instalações precárias, a total ausência de subsídios para organizar o trabalho pedagógico e uso de metodologia desconexa o resultado era desolador. "De fato, o serviço escolar estava reduzido na Bahia à alfabetização rudimentar e à subvenção a escolas particulares feita pelas prefeituras municipais.” (NUNES, 2010, p.17). No Relatório do Serviço de Instrução Pública do Estado da Bahia, publicado em 1928, Teixeira denuncia: “[...] até 1924, não tinhamos praticamente programmas. O professor possuia uma indicação muito geral do trabalho (organização de 1920) e tudo mais era dado pela pratica e methodos pessoaes de cada um". (TEIXEIRA, 1928).

As constatações descritas em Relatório de gestão exigiram a definição de prioridades para as ações da Inspetoria, entre elas a organização de um programa de ensino condizente com as expectativas sobre o ensino e a profissionalização da docência. Ao assumir o cargo, Anísio Teixeira: 
Lança-se ao exame das condições materiais e humanas em que as escolas baianas cumpriam seu papel e não seria difícil concluir que tudo necessitava de renovação. Difícil, porém, renovar pois além da pouquidade dos recursos, a parte burocrática do ensino dominava os serviços e, mais que os serviços, a própria mentalidade da administração escolar. (LIMA, 1978, p.39).

Enfrentando os dilemas expostos, Anísio Teixeira iniciou sua longa trajetória de vida pública a serviço da educação brasileira. Suas lutas e intervenções pela estruturação de uma escola pública organizada, democrática e universal iniciaram nesta gestão estadual e irradiaram-se pelo país em diferentes esferas públicas no decorrer do século XX.

\section{Qual o encaminhamento para solucionar os problemas encontrados?}

Para enfrentar a situação calamitosa com a qual se deparou, Anísio Teixeira propôs uma ampla reforma na educação baiana vislumbrando "[...] um grande movimento de reorganização, que firmasse uma concepção legítima de escola primária, estabelecesse uma ampla e universal difusão desse ensino e prestigiasse, dando-lhe a dignidade de direito, o professor primário." (ABREU, 1960, p.21). Para esta reorganização investiu na profissionalização e capacitação docente, na estruturação e expansão do sistema educacional, na revisão dos programas. De maneira geral, segundo Abreu (1960), a reforma encampada por Anísio Teixeira para esta primeira gestão da educação baiana pode ser assim sintetizada:

1. Investigação cuidadosa dos problemas educacionais na Bahia. Os resultados desses estudos servirão de base para um programa educacional progressivo e de longa duração.

2. Expansão do sistema escolar em um sistema modesto de educação secundária.

3. Revisão geral dos programas. As necessidades locais e os interesses e aptidões dos alunos serão os fatores de orientação dessa revisão.

4. Aperfeiçoamento dos métodos de ensino.

5. Reorganização das escolas rurais, para cuidar-se intensivamente da educação adulta.

6. Reorganização das Escolas Normais.

7. Criação de um 'bureau' de investigações pedagógicas na Diretoria Geral de Instrução. (ABREU, 1960, p.34). 
O investimento em capacitação profissional para enfrentar os problemas mapeados era considerado por Anísio a coluna dorsal de todo trabalho, a começar por ele mesmo. Nunes (2010) nos recorda que foi em meio a todas essas iniciativas de mudanças na gestão educacional que Anísio optou pela realização das viagens pedagógicas em busca de experiências que pudessem auxiliar na resolução dos problemas encontrados em sua terra:

Graças a essas circunstâncias, travou contato com uma literatura pedagógica e um sistema público de educação que não conhecia. A primeira viagem à América durou sete meses e foi realizada em 1927. Nela Anísio Teixeira iniciou-se no pensamento de John Dewey (18591952), travou relações de amizade com Monteiro Lobato (1882-1948), na ocasião, adido comercial em Nova York, realizou excursões pedagógicas e ainda preparou o terreno para uma visita mais prolongada àquele país em meados de 1928 e 1929, quando teve oportunidade de estudar. (NUNES, 2010, p.18).

A partir do conhecimento de teorias educacionais modernas, de novas metodologias, de novos experimentos e do funcionamento e organização de outros sistemas educacionais, experiências estas adquiridas nas viagens pedagógicas, ele vislumbrou caminhos para a reorganização das escolas. "Em Anísio, o projeto educacional significava orientação e rumo a exigir métodos de ação apropriados. Como ele era, ao mesmo tempo, um pensador e um executivo, o curso exequível do projeto ganharia em suas mãos dinamismo e possibilidades". (LIMA, 1978, p.58).

Para reorganizar a escola primária e estruturar a carreira docente dando dignidade ao professor, Anísio Teixeira organizou a base legal que colocou a educação na pauta das questões políticas da época. É deste período “[...] a Lei n” . 1846, de 14 de agosto de 1925, e o Decreto $\mathrm{n}^{\circ}$. 4312, de 30 de dezembro de 1925, a primeira reformando a Instrução Pública do Estado da Bahia e o segundo aprovando o Regulamento do Ensino Primário e Normal.” (ABREU, 1960, p.11). Para o autor, o estilo dos documentos elaborados “[...] marcam positivamente a passagem de Anísio Teixeira de tal modo que, salvo legislação sobre aspectos parciais e fragmentários, constituíram a lei educacional básica da Bahia por trinta e dois anos, até que o mesmo Anísio a viesse reestruturar [...] em 1947.” (ABREU, 1960, p.11). Segundo Lima (1978, p.54): "Em 1925, a escola primária de quatro anos em que pensara Anísio estava modelada pelo artigo 65 da Lei n.1846". A concepção de escola primária, que norteou toda a reforma educacional, está no Relatório do diretor geral da instrução: 
Essa escola primaria deve ser, na forma da lei fundamental do ensino, sobretudo educativa, buscando exercitar nos meninos os hábitos de observação e raciocínio, despertando-lhes o interesse pelos ideaes e conquistas da humanidade, ministrando-lhes noções rudimentares de literatura e historia patria, fazendo-os manejar a lingua portugueza como instrumento de pensamento e da expressão; guiando-lhes as actividades naturaes dos olhos e das mãos mediante formas adequadas de trabalhos praticos e manuaes; cuidando, finalmente, do seu desenvolvimento physico com exercicios e jogos organizados e conhecimento das regras elementares de hygiene, procurando sempre não esquecer a terra e o meio a que a escola deseja servir, utilizandose o professor de todos os recursos para adaptar o ensino ás particularidades da região e do ambiente baiano. (TEIXEIRA, 1928).

Esta proposta para o ensino primário era eminentemente inovadora para os padrões tradicionais estabelecidos e arraigados. Revelavam as preocupações advindas de uma nova filosofia com a qual Anísio Teixeira se deparou em seus estudos sobre educação. O trabalho educativo pautava-se pelo exercício de hábitos de observação e raciocínio para despertar nos alunos o interesse pelos ideais e conquistas da humanidade. Neste caminho as noções de literatura e história eram consideradas fundamentais, assim como o domínio da língua vernácula, instrumento de pensamento e de expressão. Destacava-se também o trabalho com atividades manuais e treinamento físico para desenvolvimento integral do educando. Na avaliação de Lima (1978, p.43):

Tenho que a maior novidade intelectual e administrativa desse período na Bahia foi mesmo a posição de Anísio ao traçar para a educação as diretrizes de um pensamento que colocava o sistema de ensino ao serviço da reconstrução não apenas da instrução como da própria sociedade. Esse pensamento, aparelhado de substancia técnica e filosófica, mostrava na modernização do país quanto importava às conquistas de seu curso evolutivo uma concepção educacional em que elas se apoiassem.

Todo empenho na organização do plano para a educação baiana imbricava-se na relação intrínseca entre educação e desenvolvimento social. Anísio Teixeira partia do princípio de que investir em educação é vital para a construção de uma sociedade mais justa, moderna, com oportunidades para todos. Essa foi a linha mestra para a organização do programa de ensino que subsidiou a reforma educacional e concomitantemente a formação e o trabalho docente. Tamanha ousadia nesta proposta de reconfiguração da escola soava como utopia em um Estado onde a maioria da população não tinha acesso à escola alguma. 
Para concretizar a escola sonhada por Anísio Teixeira era necessário investir maciçamente na formação e profissionalização docente. No que tange à formação docente, a situação das Escolas Normais mereceu atenção especial no movimento de reorganização do ensino baiano. Abreu (1960, p.27) afirma que Anísio Teixeira situava o problema do ensino normal com rigorosa precisão, pois partia do princípio de que “[...] a formação do professor primário é, sem contestação possível, a formação especializada de um profissional". A luta pela profissionalização do magistério iniciava desde sua formação, ou seja, na necessidade da escola normal ser uma escola profissional.

Para o ensino normal, a reforma de 1925 estabeleceu "[...] a exigência de dois anos básicos de estudos de línguas, ciências, história, geografia, desenho e trabalhos manuais, dois anos de cultural geral e dois finais de formação 'estritamente profissional'.” (LIMA, 1978, p.51). Com ela também, “Equipou-se o Instituto Normal de Salvador para atender a meta profissionalizante exigida. Criaram-se duas escolas normais, uma em Caetité, que tem hoje o nome de Anísio, e outra em Feira de Santana". A necessidade de docentes no interior era absoluta, contudo, uma das dificuldades sinalizadas no relatório de 1928 era o acesso às poucas escolas normais do interior e contratação de profissionais. Para resolver esse problema Anísio Teixeira sugeriu a criação de internatos para abrigar os professores em formação, sem eles, dado as dimensões geográficas do estado e a situação financeira da população os avanços seriam lentos. Embora os argumentos fossem contundentes, o investimento necessário para realizar esse projeto era muito alto e não foi possível concretizá-lo.

O foco na formação do professor era central na perspectiva de Anísio Teixeira, ainda assim, nem todas as tentativas foram exitosas. Contudo, a reforma encampada na Inspetoria era ampla e houve conquistas importantes em relação à profissionalização docente. Segundo texto do Relatório de 1928: "Esta Diretoria se empenhou, desde esse tempo, para a modificação da escola primaria. Deu aos professores cursos de férias. Reorganizou o programma escolar. Distribuiu, pelos inspectores escolares, assistencia e estimulo aos professores" (TEIXEIRA, 1928). Em relação à profissionalização Lima (1978, p.51) sinaliza as mudanças instituídas por Anísio Teixeira:

Pela reforma fixaram-se novos padrões de vencimentos e instituíramse cursos de férias de $1^{\circ}$ a 20 de janeiro nas Escolas Normais, o primeiro dos quais teve lugar em 1927, e destinavam-se não só a indicar a orientação moderna do ensino como a estabelecer a correlação entre as disciplinas. Abriam-se ao ensino perspectivas de 
interesse intelectual e didático, criando novo estimulo além da expectativa burocrática da nomeação e remoção.

Como afirmamos, o trabalho docente era vital em toda a proposta de reorganização do ensino, Anísio acreditava que sem investimento nele pouco se efetivaria, por isso insistia por diferentes vias para tentar elevar a educação ao primeiro plano nos compromissos políticos e econômicos do Estado. Todo empenho visava: “[...] a elevação do nível teórico do educador que, mesmo lidando com uma realidade pobre de recursos, desprovida de pessoal preparado, não raro hostil e preconceituosa, não abandonava a ferramenta intelectual com que investia contra o paredão do atraso educacional". (LIMA, 1978, p.57).

Ainda segundo Lima (1978, p.57), na perspectiva de Anísio: “[...] Era impossível divisar o futuro pelos olhos da rotina ou do atraso. Partir ao encontro do futuro exigia, no terreno educativo, capacitação teórica e pés fincados no chão". O direcionamento do trabalho era este, muito estudo, coerência, dedicação e dignidade profissional: “[...] Os resultados podiam ser modestos, até medíocres, mas a orientação estava dada: o professor seria necessariamente um profissional, jamais amador improvisado". (LIMA, 1978, p.54).

Toda diligência em organizar a base legal para subsidiar as ações da Inspetoria de Ensino e todo esforço político para inserir a educação no orçamento do Estado, garantindo crédito público para o ensino no Estado da Bahia, tiveram resultados. Segundo Viana Filho (1990, p.45) “[...] graças ao apoio de Góes Calmon, Anísio lograra a multiplicação dos pães” nesta primeira gestão. “As matrículas, no ensino primário, ascenderam de $47 \mathrm{mil}$, em 1924, para 79 mil, em 1927. As despesas com o ensino subiram de 4\% para 12\% da receita do Estado". Ainda segundo Viana Filho (1990, p.45), Anísio assim escreveu, em 1928, com visível satisfação pelo realizado:

$\mathrm{O}$ interesse pela instrução é uma realidade à vista de todos. As menores localidades estão aprendendo a ter orgulho pelas suas coisas de ensino e a se porfiar nas conquistas de educação. A construção dos prédios escolares pelos municípios com auxílio do Estado, a solicitação de localização de escolas, o interesse local pelo bom mestre, a fiscalização exercida por patriotismo, o estímulo do professor para se aperfeiçoar e progredir; são alguns exemplos demonstrativos desse largo, verdadeiro interesse que está a percorrer todo o Estado nas coisas de educação.

Em meio às conquistas, resultantes de uma árdua luta para implementar as ações que julgava básicas, aproximou-se o final de sua primeira gestão na Inspetoria de 
Ensino da Bahia. O mandato de Góes Calmon terminou e em 1928 o novo governador, Vital Soares, assumiu o cargo, convidando Anísio para continuar à frente da pasta de educação. Segundo Lima (1978, p.55), Anísio:

[...] apresenta uma série de sugestões para a reorganização progressiva do sistema educacional baiano, sugestões que reivindicavam nomeadamente expansão do sistema escolar, reconstrução educativa da escola primária, aumento da escolaridade pública obrigatória até o nível secundário, aprimoramento dos métodos de ensino, reorganização das escolas rurais para cuidar-se intensivamente da educação adulta, reestruturação das Escolas Normais e dos Ginásios e demandavam recursos financeiros e técnicos, enriquecimento dos quadros profissionais, cursos de aperfeiçoamento inclusive no exterior.

Por meio de sugestões, sinalizava o que ainda precisava ser feito para a reorganização do sistema educacional. O relatório era um instrumento para viabilizar meios e recursos para dar continuidade ao trabalho iniciado. Para argumentar, Anísio apresentava dados sobre o ensino e as condições sociais na Bahia evidenciando os avanços. Ainda que os dados fossem consistentes, que houvesse amparo legal e necessidade social para ampliá-lo esbarrou nas questões políticas do Estado. Viana Filho (1990, p.45) sintetiza o término da primeira gestão:

Corridos quatro anos sobre a reforma, período no qual estivera na Europa e nos Estados Unidos, entendera oportuno reformar-se a reforma, cujas deficiências pudera observar. [...] humilde, pondo a verdade acima de tudo, não ocultou as falhas observadas na reforma de que fora o responsável. Chegara a hora de aperfeiçoá-la. Havendo Góes Calmon deixado o Governo, substituído por Vital Soares, este evitou agitar novamente as águas, repetindo os inevitáveis debates sobre as inovações de Anísio, que sentiu chegada a hora de recolher as velas. Foi o que fez, demitindo-se.

Anísio Teixeira afastou-se do comando da educação, em novembro de 1929, porque não conseguiu cobertura suficiente ao seu "Plano de Reorganização Progressiva do Sistema Educacional Baiano". A receptividade e apoio do novo governador foram insuficientes se comparados às necessidades e urgências educacionais. O projeto de reorganização e modernização da educação será retomado na segunda gestão dele na Bahia (1947-1951).

\section{Considerações finais}


As contribuições de Anísio Teixeira para a organização do ensino público transitaram em diferentes esferas no decorrer de toda sua vida pública. Este texto procurou destacar as ações encampadas em sua primeira experiência na gestão da educação pública. Como vimos, o quadro que assumiu para administrar no Estado da Bahia era desolador. Para enfrentar e resolver a situação estabeleceu prioridades para desenvolver o trabalho que julgou ser elementar. Tais ações prioritárias, passado quase um século da reforma instituída, devem ser retomadas e estudadas, pois, se constituem em caminhos possíveis para superar problemas seculares da educação brasileira. O que fez Anísio Teixeira que pode nos orientar tanto tempo depois?

Dentre as prioridades selecionadas em uma ampla reforma de ensino, elegeu a profissionalização e capacitação docente como ação elementar coadunada com a organização de um programa de ensino para reorganização da escola. Em outras palavras, nos ensina que o investimento na carreira e formação docente é fundamental para a vitalidade da escola. Não há organização escolar que prescinda estudos aprofundados sobre o processo de ensino e aprendizagem. O forte investimento na profissionalização e formação docente com condições básicas de estudos e aplicação na organização do trabalho pedagógico é estratégia importante quando se trata de reforma educacional. Ensinou-nos também que este objetivo não se alcança sem compromisso político e investimentos adequados.

\title{
ANÍSIO TEIXEIRA, THE MANAGEMENT AND FIRST CHALLENGES IN THE EDUCATION INSPECTORATE AT BAHIA (1924-1929)
}

\begin{abstract}
This work is part of research project under development in the doctorate school in education, which highlights the contributions of Anisio Teixeira for the organization of the Brazilian public school. To this text, we selected the actions taken during his first experience in education, when he assumed the Education Inspectorate at Bahia in 1924. This is a bibliographic study anchored in the author's own records and other intellectuals who devoted themselves to his legacy. The results point to the reorganization of shares of primary school with the development of an educational program and redefinition of your goals and methods, concomitantly, stresses the need for professionalization and teacher training to carry out the reform undertaken.
\end{abstract}

KEYWORDS: Primary school. Public school. Teacher training. 


\section{REFERÊNCIAS}

ABREU, J. Anísio Teixeira e a educação na Bahia. In: ABREU, J. et al. Anísio Teixeira: pensamento e ação. Rio de Janeiro: Civilização Brasileira, 1960. p.1-68.

LIMA, H. Anísio Teixeira estadista da educação. Rio de Janeiro: Civilização Brasileira, 1978.

NUNES, C. Anísio Teixeira. Recife: Fundação Joaquim Nabuco, Massangana, 2010. (Educadores MEC).

TEIXEIRA, A. Relatório apresentado ao Ex. Sr. Cons. Bráulio Xavier da Silva Pereira, Secretário do Interior, Justiça e Instrução Pública pelo Diretor Geral da Instrução Pública, para ser encaminhado ao governador do Estado da Bahia. Salvador: Imprensa Oficial do Estado, 1928. Disponível em: <http://www.bvanisioteixeira.ufba.br/>. Acesso em: 14 jul. 2015.

VIANA FILHO, L. Anísio Teixeira e a polêmica da educação. Rio de Janeiro: Nova Fronteira, 1990. 